\title{
Promoting Research and Best Practices in Subject Reference Structures
}

\section{A Decade of Work by the Subject Analysis Committee}

\section{David Miller, Tony Olson, and Sara Shatford Layne}

In 2004, the ALCTS Cataloging and Classification Section Subject Analysis Committee (SAC) produced the report "Recommendations for Providing Access to, Display of, Navigation within and among, and Modifications of Existing Practice Regarding Subject Reference Structures in Automated Systems." This document is one important outcome of nearly ten years' work by three SAC subcommittees investigating the theoretical, pragmatic, and political dimensions of improving subject access through better use of reference structure data. The work of those subcommittees is reviewed and their recommendations are described and summarized. Potential future effects of the report are discussed, as is a snapshot view of several major automation systems' current compliance with the recommendations.

The value and importance of using controlled vocabularies for subject 1 retrieval has been well established. ${ }^{1}$ Research has shown that the best results from subject searches in terms of recall and precision are achieved with a combination of keyword and controlled vocabulary searching. ${ }^{2}$ However, subject searching remains problematic in online catalogs. Usage studies have shown that although subject searches constitute the majority of searches in online catalogs, they exhibit a high rate of failure. ${ }^{3}$

Several reasons contribute to the failure of subject searches. Some can be traced to problems with the use of controlled vocabularies, which include shortcomings in the reference structures used in online catalogs. Some of these deficiencies are:

David Miller (dmiller@curry.edu) is Head of Technical Services, Levin Library, Curry College, Milton, Mass. Tony Olson (ajolson@northwestern.edu) is Head of Technical Services, Galter Health Sciences Library, Nothwestern University, Evanston, III. Sara Shatford Layne (slayne@library.ucla.edu) is Principal Cataloger, University of California-Los Angeles.
- lack of cross references; ${ }^{4}$

- insufficient or lack of references connecting related broader and narrower terms; ${ }^{5}$

- no access to reference structures in keyword searches; and ${ }^{6}$

- no references linking equivalent terms from different controlled vocabularies residing in the same online catalog.

Additional factors include: 
- problems within the syndetic structures of controlled vocabularies;

- failure on the part of automated systems to utilize fully the existing reference structures in online catalogs;

- failure on the part of automated systems to include and provide access to subject reference structures in keyword indexes in online catalogs; and

- incomplete implementation of reference structures in online catalogs by librarians and system implementers.

Beginning in the mid-1990s, the Subject Analysis Committee (SAC) of the Association for Library Collections \& Technical Services (ALCTS) Cataloging and Classification Section (CCS) sponsored investigations of the potential for improved subject access in catalogs through exploiting the conceptual links among controlled subject terms. Three successive SAC subcommittees, in existence between 1995 and 2004, studied and advocated subject reference indexing and display issues. See table 1 for a summary outline of these subcommittees and their work. One of the outcomes of the subcommittees' work is a document titled Recommendations for Providing Access to, Display of, Navigation within and among, and Modifications of Existing Practice Regarding Subject Reference Structures in Automated Systems, which was approved by SAC at the 2004 American Library Association (ALA) Midwinter Meeting. ${ }^{7}$ This paper will provide background, development, summary description of the recommendations, and a snapshot view of the current state of the library systems industry with regard to these recommendations, at least as reflected by five major automated systems.

\section{Background}

The investigations began with the authorization of the Subcommittee on Subject Relationships/Reference Structures (SSRRS), which came into being between the 1995 ALA Midwinter Meeting and Annual Conference. ${ }^{8}$ The impetus was a discussion during the previous year of Library of Congress (LC) policy on see-also references, where concerns were expressed that:

- library catalog users need a positive response to the terms they use in a search (entry vocabulary);

- synonymous terms used in Library of Congress subject headings (LCSH) should be linked to one another in a way helpful to the user;

- the hierarchical structure of LCSH see-also references (broader term, narrower term, related term) could help users navigate subject categories and find those of interest to them;

- few online library catalogs made see-also references available, and most of those that did linked from broader terms to narrower terms but not the other way around; and

- more related-term references between synonymous headings were needed in LCSH, including headings

Table 1. Subcommittees of the Subject Analysis Committee studying subject reference indexing and display issues.

\section{Subcommittee}

Subcommittee on Subject

Relationships/Reference

Structures (SSRRS)

Subcommittee to Promote Subject Relationships/ Reference Structure (SPSRRS)

Subcommittee on Subject Reference Structures in Automated Systems (SRSAC)
Years

1995-1997

\section{Presentations}

Final Report

Final Report to the ALCTS/CCS Subject Analysis Committee Subcommittee on Subject Relationships/Reference Structures (June 1997),

1997-2000 Discussion forums at ALA Midwinter meetings(19982000); "Oh Say, Can We See? See Also? Subject Referencing Possibilities in OPACs" (Program at 1999 ALA Annual Conference)

2001-2004

"Getting the Most Out of Subject References in the Online Catalog: Better Than It Used to Be?" (Program at 2003 ALA Annual Conference)
[Final Report] Report to the ALCTS CCS Subject Analysis Committee (July 2000)

[Final Report] Recommendations for Providing Access to, Display of, Navigation within and among, and Modifications of Existing Practice Regarding Subject Reference Structures in Automated Systems (Dec. 1, 2003)

\section{Report URL}

www.ala.org/ala/alctscontent/ catalogingsection/catcommittees/ subjectanalysis/subjectrelations/ finalreport.htm (accessed Oct. 30, 2004)

www.ala.org/ala/alctscontent/ catalogingsection/catcommittees/ subjectanalysis/promotesubjectre/ FinalReport.doc (accessed Nov. 30, 2004)

www.ala.org/ala/alctscontent/ catalogingsection/catcommittees/ subjectanalysis/subjectreference/ RefStructuresFinal.doc (accessed Oct. 30, 2004) 
already linked indirectly through links to the same broader term.

As noted in the subcommittee's Final Report, its "creation was one result of a discussion of how (and why) to promote the display and use of broader-term reference structures." The work produced by the subcommittee went well beyond this single aspect, however. Its charge included the following tasks: "To investigate: [i] the kinds of relationships that exist between subjects, the display of which are likely to be useful to catalog users; [ii] how these relationships are or could be recorded in authorities and classification formats; [iii] options for how these relationships should be presented to users of online and print catalogs, indexes, lists, etc." 10 The group took, therefore, a broad view of the nature of subject relationships, their potential encoding, and presentation, not limited by the capabilities of existing library information systems.

SSRRS's Final Report includes a number of appended documents that still reward study. ${ }^{11}$ These are, among others, a taxonomy of no fewer than 165 subject relationships, presented both alphabetically and hierarchically; a checklist of subject relationships suitable for use in information retrieval; a report on reference displays provided by selected CD-ROM-based indexes of the period; a position paper on the importance of subject referencing in online public access catalogs (OPACs); a review of research topics; and an extensive bibliography.

The potential for improvements in subject retrieval implied by the subcommittee's research can be seen in two examples of semantic analyses quoted in the report. The term pair RAIN/CLOUD is analyzed as follows: "Associative/pairs from same hierarchy/causal relationships/dependency relationships/entity-precursor relationships." ${ }^{.2}$ The term pair WOMEN/WOMAN is analyzed as "Equivalence/same lexical term variants/morphological variants/inflectional suffix variants/irregular plural-singular pairs." ${ }^{.13}$ Regarding these analyses, the report states, "One's first reaction is that it is not necessary to encode semantic relationships as specific as these. But on what basis can we make that judgment?"14 The conceptual net should be cast widely in order to be assured of sufficient specificity as new modes of retrieval, including concept mapping and information visualization, are developed. Users at each different level of sophistication should have more options than a single, advanced set of search options and outcomes.

Having described the big picture regarding subject relationships, SSRRS presented several findings and recommendations, some of which pointed forward to the work of the next two subcommittees. The subcommittee recommended improvements in the display of currently encoded relationships-broader terms (BT), narrower terms (NT), and related terms $(\mathrm{RT})$ - and the clustering of reference terms based on relationship type. In addition, the subcommittee recommended that SAC should establish further subcommittees for various related purposes, including producing a program on subject relationships and reference structures at an ALA Conference.

The successor Subcommittee to Promote Subject Relationships/Reference Structures (SPSRRS) took the latter task of communicating with the broader community most seriously. ${ }^{15}$ Established at the 1997 ALA Annual Conference, its charge included the following: "To promote the display of currently encoded subject relationships/reference structures to system designers (for example, OPACs, CD-ROMS, periodical indexes, thesauri). To provide discussion forums and/or programs on currently encoded subject relationships/reference structures."16 Thus, while the focus of this subcommittee narrowed to currently encoded relationships, as compared with the in-depth examination provided by the previous group, it also broadened to include a task of outreach and communication. To carry out the second part of its charge, SPSRRS hosted discussion forums at the 1998-2000 ALA Midwinter Meetings and the 1998 and 2000 ALA Annual Conferences. The subcommittee also developed a program for the 1999 ALA Annual Conference. ${ }^{17}$

Michel concluded the 1999 program with a talk that, perhaps unexpectedly for some attendees, specifically addressed the nuts and bolts of making change happen. ${ }^{18}$ Michel's talk brought home the reality that customary forms of advocacy, typically involving the presentation of research results, may be inadequate to address industrywide deficits. In fact, the subcommittee encountered difficulties in carrying out the first part of its charge, specifically in its efforts to communicate directly with the vendor community. The subcommittee drafted a letter that it intended to send to vendors with the intention of promoting dialogue. SAC, however, did not approve the letter, "in part because of concerns that [it] would not reach the 'right' people in the targeted companies." ${ }^{19}$ At both the Midwinter Meeting and Annual Conference in 1999, subcommittee members visited the exhibit booths of database and automated system vendors, and in some instances were able to identify the appropriate contact persons. In addition, the discussion forums were promoted to vendors via e-mail, with some success in terms of encouraging attendance.

In its Final Report, SPSRRS described a somewhat ambiguous, if evolving, situation regarding the importance of promoting subject reference structures. The implementation of "some form of LCSH thesaurus-type display" had become more common in catalogs (though less so in index databases), but was frequently incomplete in terms of necessary indexing, searching, and display features. ${ }^{20} \mathrm{~A}$ seemingly stubborn "misunderstanding of the nature and potential of controlled-term subject referencing," as compared with keyword-based retrieval, remained. ${ }^{21}$ Finally, 
the issue of how best to communicate with the vendor community was still somewhat vexing. The subcommittee emphasized that "the approval process required of any official communication is too slow for the sort of dialogue that should be taking place. ${ }^{\prime 22}$ Non-customers faced difficulties in sharing concerns directly with vendors, even in an informal way.

Many, although not all, subcommittee members wished to continue the group's work. The Final Report included a recommendation for reauthorization, suggesting that the charge be amended to include (among other points) that the subcommittee "explore the issues surrounding the use of thesaurus-like subject referencing structures in bibliographic databases ... and produce a position paper on the subject." ${ }^{\prime 23}$ At its meeting at the 2000 Annual Conference, SAC discussed this proposal and decided to form a new subcommittee. The Subcommittee on Subject Reference Structures in Automated Systems (SRSAS), the third in this series of subcommittees, was appointed by the 2001 Midwinter Meeting. ${ }^{24}$ The new subcommittee's charge stated that it should: "Explore issues related to subject reference structures in the OPAC environment. Develop a position paper to guide systems designers in presenting syndetic structures effectively." ${ }^{25}$ In focusing on a position paper (which eventually became the twenty-six recommendations discussed in this paper) rather than direct communication with vendors, the new subcommittee approached the problem from a perspective suggested by SPSRRS in its Final Report: "it may be that building awareness of subjectreferencing issues within the library community as a whole will ultimately reach the vendors more efficiently." ${ }^{26}$

SRSAS, in discussing its charge at the 2001 Annual Conference, decided that the most effective approach would be to concentrate on what can be done with existing subject access tools, such as the LCSH or Medical Subject Headings (MeSH), and their established reference structures (BT, NT, RT). Subcommittee members initially mapped the conceptual territory to be covered by preparing reports on a variety of topics, including:

- uses of subject vocabularies and searching tools;

- ability to browse the structure of subject vocabularies;

- complex see and see also references;

- note fields in authority records;

- relationships between main headings and subdivisions;

- display of references among multiple subject vocabularies;

- genre and topical terms and reference structures;

- hypertext links related to the subject fields in bibliographic records;

- incorporation of reference structures in keyword searches of bibliographic records;

- names and titles as subjects;
- normalization and sort order;

- blind references and missing links;

- geographic subject headings;

- reference structures and limits by location; and

- vocabulary of display.

The reports described the issues associated with each topic and, when appropriate, included examples that illustrated how these issues are or might be addressed in existing systems. Subcommittee members and guests discussed the reports at the 2002 Midwinter Meeting. Based on the reports and subsequent discussions, the subcommittee formulated twenty-six recommendations for the utilization of subject reference structures in automated systems. ${ }^{27} \mathrm{~A}$ summary of the recommendations also was presented at a program organized by SRSAS at the 2003 ALA Annual Conference. ${ }^{28}$

\section{Recommendations}

The recommendations concentrate on maximizing the use of existing subject reference structures in automated systems and emphasize subject reference structures supported by MARC 21 authority and bibliographic records. The recommendations include the concepts of guiding users to preferred terms from synonyms (or approximate synonyms), and also guiding users who wish to narrow, broaden, or change the scope of an initial search. Although these recommendations are directed at library systems that use MARC 21 authority and bibliographic records, the recommendations also could be used in implementing other automated systems that use different metadata schemes.

Recommendations 1 through 24 are intended for system designers, for institutions making choices among systems, for implementing and customizing systems, and for requesting enhancements to existing systems. Recommendations 25 and 26 are aimed not at system designers and implementers, but at that portion of the library community responsible for setting policies and practices regarding the creation of MARC 21 authority records. The recommendations are grouped into four sections: (I) recommendations for providing access to reference structures; (II) recommendations for display of headings and reference structures; (III) recommendations for providing navigation within and among reference structures; and (IV) concerns for the future: recommendations for librarians for modification of existing library practices in the creation of subject reference structures. The recommendations and their justifications are given with examples illustrating the implementation of some of the recommendations in the appendix. Additional examples as well as discussions concerning implementation issues and problems can be found in the full subcommittee report. ${ }^{29}$ 


\section{Current State of Subject Reference Structures in Online Catalogs}

Five automated library systems were surveyed by the authors of this paper to determine which of the twenty-four recommendations targeted at system vendors and users have actually been implemented. Recommendations 25 and 26 were not included in this survey because they are directed at librarians. The catalogs were from the following systems: Aleph500 (ExLibris [USA]), AMICUS (Library and Archives of Canada), Millennium (Innovative Information Systems), Unicorn (Sirsi), and Voyager (Endeavor Information Systems). Data for the survey were gathered through an examination of five online catalogs by the authors, in consultation with librarians who have implemented the systems. ${ }^{30}$ Information also was gathered from presentations by representatives of the five systems at the 2003 SRSAS program. ${ }^{31}$ The results are shown in table 2. (In order to provide an overall view of which recommendations have been implemented, the specific systems are not identified, except as System A, System B, and so on.)

As can be seen from the table, the five systems are essentially at the same level of implementation. Most of the systems uniformly provide (with a few exceptions) some basic functionality, such as:

- Indexing and display of references from 4xx and 5xx fields; for example, see [from], see also [related, narrower andbroader] references (recommendation 1).

- Hyperlinks to indexes, which include reference structures, from subject headings in bibliographic records (recommendation 5); and hyperlinks from displayed references (recommendation 23).

- Inclusion of names and titles in subject searches and indexes (recommendation 8).

- Identification of source vocabulary (recommendation 13); and in a display of subject headings, the number of records retrieved for each heading (recommendation 14).

- Display of complex "see" and "see also" references from 260 and 360 fields (recommendation 17).

- Browse subject searches (recommendation 22).
On the other hand, a number of important recommendations (involving more advanced and sophisticated functionality) have not been implemented by most of the systems. These include:

- Inclusion of authority records in keyword indexes (recommendation 2) and provision of access to subject references in keyword indexes (recommendation 3), which none of the systems currently provide.

- Use of punctuation and subfielding to provide meaningful displays of subject headings (recommendation 11), which none of the systems currently provide.

- Display of references to headings with 0 postings if the heading occurs only in a subdivided form (recommendation 19), which only two of the systems currently provide.

- Indexing and provision of references from 7xx linking entry fields in authority records (recommendation 24 ), which only one system currently provides.

Table 2. Implementation of the recommendations for subject reference structures by five automated systems.

\begin{tabular}{|c|c|c|c|c|c|}
\hline Recommendation & System A & System B & System C & System D & System E \\
\hline 1 (Index 4XX fields) & $\mathrm{Y}$ & $\mathrm{Y}$ & $\mathrm{Y}$ & $\mathrm{Y}$ & $\mathrm{Y}$ \\
\hline 1 (Index 5XX fields) & $\mathrm{Y}$ & $\mathrm{Y}$ & $\mathrm{Y}$ & $\mathrm{Y}$ & $\mathrm{Y}$ \\
\hline 1 (Index 7XX fields) & $\mathrm{N}$ & $\mathrm{E}$ & $\mathrm{Y}$ & $\mathrm{N}$ & $\mathrm{N}$ \\
\hline 1 (Display 260 fields) & $\mathrm{Y}$ & $\mathrm{Y}$ & $\mathrm{N}$ & $\mathrm{Y}$ & $\mathrm{Y}$ \\
\hline 1 (Display 360 fields) & $\mathrm{Y}$ & $\mathrm{Y}$ & $\mathrm{N}$ & $\mathrm{Y}$ & $\mathrm{Y}$ \\
\hline 2 & $\mathrm{E}$ & $\mathrm{E}$ & $\mathrm{N}$ & $\mathrm{N}$ & $\mathrm{N}$ \\
\hline 3 & $\mathrm{~N}$ & $\mathrm{~N}$ & $\mathrm{E}$ & $\mathrm{E}$ & $\mathrm{N}$ \\
\hline 4 & $\mathrm{Y}$ & $\mathrm{Y}$ & $\mathrm{Y}$ & $\mathrm{Y}$ & $\mathrm{Y}$ \\
\hline 5 & $\mathrm{Y}$ & $\mathrm{Y}$ & $\mathrm{Y}$ & $\mathrm{N}$ & Y \\
\hline 6 & $\mathrm{Y}$ & $\mathrm{Y}$ & $\mathrm{N}$ & $\mathrm{N}$ & $\mathrm{Y}$ \\
\hline 7 & $\mathrm{U}$ & $\mathrm{Y}$ & $\mathrm{Y}$ & $\mathrm{N}$ & $\mathrm{Y}$ \\
\hline 8 & Y & $\mathrm{Y}$ & $\mathrm{Y}$ & $\mathrm{Y}$ & $\mathrm{Y}$ \\
\hline 9 & $\mathrm{~N}$ & $\mathrm{~N}$ & $\mathrm{~N}$ & $\mathrm{~N}$ & $\mathrm{~N}$ \\
\hline 10 & $\mathrm{~N}$ & $\mathrm{Y}$ & $\mathrm{Y}$ & $\mathrm{Y}$ & Y \\
\hline 11 & $\mathrm{~N}$ & $\mathrm{~N}$ & $\mathrm{~N}$ & $\mathrm{~N}$ & $\mathrm{~N}$ \\
\hline 12 & $\mathrm{Y}$ & $\mathrm{P}$ & $\mathrm{Y}$ & $\mathrm{N}$ & $\mathrm{Y}$ \\
\hline 13 & $\mathrm{~N}$ & $\mathrm{U}$ & $\mathrm{Y}$ & $\mathrm{Y}$ & $\mathrm{Y}$ \\
\hline 14 & $\mathrm{Y}$ & $\mathrm{Y}$ & $\mathrm{Y}$ & $\mathrm{Y}$ & $\mathrm{Y}$ \\
\hline 15 & $\mathrm{Y}$ & $\mathrm{N}$ & $\mathrm{P}$ & $\mathrm{P}$ & $\mathrm{Y}$ \\
\hline 16 & $\mathrm{~N}$ & $\mathrm{P}$ & $\mathrm{P}$ & $\mathrm{Y}$ & $\mathrm{Y}$ \\
\hline 17 & $\mathrm{Y}$ & $P$ & $\mathrm{~N}$ & $\mathrm{Y}$ & $\mathrm{Y}$ \\
\hline 18 & $\mathrm{~N}$ & $\mathrm{~N}$ & $\mathrm{~N}$ & $\mathrm{~N}$ & $\mathrm{Y}$ \\
\hline 19 & $\mathrm{Y}$ & $\mathrm{Y}$ & $\mathrm{U}$ & $\mathrm{N}$ & $\mathrm{U}$ \\
\hline 20 & $\mathrm{U}$ & $\mathrm{Y}$ & $\mathrm{U}$ & $\mathrm{Y}$ & $\mathrm{Y}$ \\
\hline 21 & $\mathrm{~N}$ & $\mathrm{Y}$ & $\mathrm{N}$ & $\mathrm{Y}$ & $\mathrm{N}$ \\
\hline 22 & $\mathrm{Y}$ & $\mathrm{Y}$ & $\mathrm{Y}$ & $\mathrm{Y}$ & $\mathrm{Y}$ \\
\hline 23 & $\mathrm{Y}$ & $\mathrm{Y}$ & $\mathrm{Y}$ & $\mathrm{Y}$ & $\mathrm{Y}$ \\
\hline 24 & $\mathrm{~N}$ & $\mathrm{E}$ & $\mathrm{Y}$ & $\mathrm{N}$ & $\mathrm{N}$ \\
\hline
\end{tabular}

Note: $\mathrm{Y}=$ Yes, system has recommended functionality; $\mathrm{N}=\mathrm{No}$, system does provide recommended functionality; $\mathrm{P}=$ system provides partial functionality, but not all of the functionality recommended; $E=$ forthcoming enhancement will provide functionality; $U=$ functionality undetermined. For Recommendation 1, the indexing and/or display of each field or group of fields is indicated. 
Some of the vendors are planning to enhance their systems in order to provide some of the additional functionality specified in the recommendations. These systems are identified in table 1 by the code $\mathrm{E}$, which indicates an enhancement that a vendor is committed to and is actively developing for a version to be released within the next few years. Specifically, two vendors are planning to provide keyword indexing of authority records in their systems (recommendation 2), two other vendors are planning to introduce keyword-in-heading searches that provide access to reference structures (recommendation 3), and one vendor is planning to index the 7XX linking entry fields in authority records and generate equivalent term references from these fields (recommendation 24).

\section{Conclusions}

As stated earlier, building awareness in the library community and communicating with system vendors about subject referencing issues was a major problem identified by SPSRRS. The creation of the document containing the recommendations for implementing subject reference structures has the potential to solve this problem. Library and Archives of Canada and the four vendors that participated in the 2003 SRSAS program have received copies of the subcommittee's Final Report. At that program, the representatives discussed how some of the recommendations have been or will be implemented in their respective systems.

Also as noted above, one of the intended uses of the recommendations is to assist users in the formulation of enhancement requests for automated systems. This has already begun, as the recommendations have been used for developing enhancement requests for two systems. Users of other systems may choose to do likewise. Furthermore, current users of automated systems will use the recommendations to implement fully all of the functionality that is present in their systems.

The survey of the five automated systems shows that considerable progress has been made in the utilization of subject references structures in online catalogs since the formation of the first SAC subcommittee in 1995. However, much still needs to be done in order to exploit the power of controlled vocabularies and their reference structures. SRSAS's recommendations can be used as the starting point for further developments in the use of subject reference structures.

\section{References and Notes}

1. F. W. Lancaster, Vocabulary Control for Information Retrieval, 2d ed. (Arlington, Va.: Information Resources Pr., 1986); Thomas Mann, Library Research Models: A Guide to Classification, Cataloging and Computers (New York: Oxford
Univ. Pr., 1993); and Arlene G. Taylor, "On the Subject of Subjects," Journal of Academic Librarianship 21, no. 5 (Nov. 1995): 486-91.

2. C. P. R. Dubois, "Free Text vs. Controlled Vocabulary: A Reassessment," Online Review 11, no. 4 (Aug. 1987): 243-52. Dubois summarizes the research done on using keyword indexing and controlled vocabularies for subject retrieval.

3. Ray R. Larson, "Between Scylla and Charybdis: Subject Searching in the Online Catalog," Advances in Librarianship 15 (1991): 178-90; Christine L. Borgmann, "Why Are Online Catalogs Still Hard to Use?" Journal of the American Society for Information Science 47, no. 7 (July 1996): 493-502; Joseph R. Mathews, "Time for New OPAC Initiatives: An Overview of Landmarks in the Literature and Introduction to WordFocus," Library Hi Tech 15, no. 1/2 (1997): 111-14; and Thomas A. Peters, "Why Smart People Fail: An Analysis of the Transaction Log of an Online Public Access Catalog," Journal of Academic Librarianship 15, no. 5 (Nov. 1989): 267-72.

4. F. H. Ayres, "Authority Control Simply Does Not Work," Cataloging \& Classification Quarterly 32, no. 2 (2001): 51-54.

5. Jane Greenberg, "Reference Structures: Stagnation, Progress, and Future Changes," Information Technology and Libraries 16, no. 3 (Sept. 1997): 108-12.

6. Marguerite E. Horn, "Garbage in, Refuse and Refuse Disposal Out," Library Resources \& Technical Services 46, no. 3 (July 2002): 98-102; Alexis J. Jamieson, Elizabeth Dolan, and Luc Declerck, "Keyword Searching vs. Authority Control in an Online Catalog," Journal of Academic Librarianship 12, no. 5 (Nov. 1986): 277-83.

7. Association for Library Collections \& Technical Services, Subcommittee on Subject Reference Structures in Automated Systems, [Final Report] Recommendations for Providing Access to, Display of, Navigation within and among, and Modifications of Existing Practice Regarding Subject Reference Structures in Automated Systems (Chicago: ALA, 2003). Accessed June 4, 2004, www.ala.org/ala/alctscontent/ catalogingsection/catcommittees/subjectanalysis/subjectreference/RefStructuresFinal.doc.

8. Members of the SAC Subcommittee on Subject Relationships/Reference Structures were Gregory Wool (chair), Jane Greenberg, Harriette Hemmasi, Patricia Kuhr, Dee Michel, Steven Riel, Gary Strawn, and Lynn El-Hoshy (Library of Congress consultant).

9. Association for Library Collections \& Technical Services, Subcommittee on Subject Relationships/Reference Structures, Final Report. (Chicago: ALA, 1997). Accessed June 4, 2004, www.ala.org/ala/alctscontent/catalogingsection/ catcommittees/subjectanalysis/subjectrelations/finalreport. htm.

10. Ibid.

11. Ibid.

12. Ibid.

13. Ibid.

14. Ibid.

15. Members of the SAC Subcommittee to Promote Subject Relationships/Reference Structures were Gregory Wool (chair), Kristin Gerhard, Stephen Hearn, Claudia Hill, Heidi 
Lee Hoerman, Gerard McKiernan, Steven Riel, and Arlene G. Taylor.

16. Association for Library Collections \& Technical Services, Subcommittee to Promote Subject Relationships/Reference Structures, [Final Report] (Chicago: ALA, 2000). Accessed June 4, 2004, www.ala.org/ala/alctscontent/catalogingsection/ catcommittees/subjectanalysis/promotesubjectre/FinalReport. doc.

17. Oh Say, Can We See? See Also? Subject Referencing Possibilities in OPACs, a program organized by the Subcommittee to Promote Subject Relationships/Refer ence Structures, Subject Analysis Committee, Association for Library Collections \& Technical Services, and held during the American Library Association Annual Conference, New Orleans, June 26, 1999. The program was moderated by Heidi Lee Hoerman and featured speakers Thomas Mann, "Referencing Considerations within OPACs"; Joseph Matthews, "Subject Referencing in Next-Generation OPACs"; Kristin Gerhard, "The Impact of Subject Cross-References on OPAC Search Results"; and Dee Michel, "Getting What We Want: the Politics of Interface Change."

18. Michel, "Getting What We Want."

19. Subcommittee to Promote Subject Relationships/Reference Structures, [Final Report].

20. Ibid

21. Ibid

22. Ibid.

23. Ibid.

24. Members of the SAC Subcommittee on Subject Reference Structures in Automated Systems were Sara Shatford Layne (chair), Diane Dates Casey, Michael D. Colby, Heidi Lee Hoerman, Tony Olson, Michelle Martin Robertson, Arlene G. Taylor, and Bruce M. Trumble.

25. Association for Library Collections \& Technical Services, Subcommittee on Subject Reference Structures in Automated Systems, Web site, Accessed June 4, 2004, www. ala.org/ala/alctscontent/catalogingsection/catcommittees/ subjectanalysis/subjectreference/subjectreference.htm.

26. Subcommittee to Promote Subject Relationships/Reference Structures, [Final Report].
27. Subcommittee on Subject Reference Structures in Automated Systems, [Final Report]. These are the recommendations referred to in the Introduction to this paper.

28. Getting the Most out of Subject References in the Online Catalog: Better than It Used to Be? a program organized by the Subcommittee on Subject Reference Structures in Automated Systems, Subject Analysis Committee, Association for Library Collections \& Technical Services, and held during the American Library Association Annual Conference, Toronto, June 21, 2003. The program was moderated by Tony Olson. In her talk, "Using Subject Reference Structures," Sara Shatford Layne presented a summary of the subcommittee's recommendations, with some examples of their application. Pam Armstrong, from the Library and Archives of Canada (L\&AC), in her talk "Navigating Bilingual Subject Headings in AMICUS," discussed L\&AC's policy of including headings from three different subject heading systems: Library of Congress Subject Headings, Canadian Subject Headings, and Répertoire de vedettes-matière in their bibliographic records, and the provision of references linking equivalent headings from the three systems in the L\&AC's online catalog, AMICUS. Representatives from four vendors of automated systems then gave brief presentations on both the current use and future development of subject reference structures in their systems. The representatives were: Shelley Hofstetler, Endeavor Information Systems, "Subject References in Voyager"; Michael Kaplan, ExLibris (USA), "Subject References in Aleph500"; Claudia Conrad, Innovative Interfaces, "Subject References in Millennium"; Berit Nelson, Sirsi, "Subject References in Unicorn."

29. Subcommittee on Subject Reference Structures in Automated Systems, Final Report.

30. Shannon Hoffman, e-mail to Tony Olson, Feb. 25, 2004; and Bruce M. Trumble, e-mail to Tony Olson, Feb. 27, 2004.

31. Armstrong, "Navigating Bilingual Subject Headings in AMICUS"; Hostetler, "Subject Access in Voyager"; Kaplan, "Subject References in ALEPH500"; Conrad, "Subject References in Millennium"; Nelson, "Subject References in Unicorn."

\section{Appendix \\ Recommendations and Justifications, with Selected Examples Showing Application Part I: Recommendations for Providing Access to Reference Structures}

1. In addition to the authorized headings in authority records (MARC 21 1XX fields), all references and linking fields in authority records should be available for indexing and/or display, including see-references (both simple and complex), see-also-references (both simple and complex), and linking fields. The relevant MARC 21 fields are: 1XX, 260, 360, $4 \mathrm{XX}, 5 \mathrm{XX}, 7 \mathrm{XX}$.

Reasons: All headings and references can be used to provide access to reference structures

Example: A topical subject authority record showing the fields to be indexed and/or displayed:

150: : $\neq$ a Cancer

360: : $\neq 1$ subdivision $\neq a$ Cancer $\neq i$ under individual organs and regions of the body, e.g. $\neq a$ Foot—Cancer

450: : :a Cancers

450: :‡a Carcinoma

450: :‡a Malignancy (Cancer) 


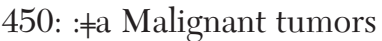

550: : $\neq \mathrm{w} g \neq \mathrm{a}$ Tumors

750: 2:‡a Neoplasms

2. If a keyword-in-record search of bibliographic records also matches a heading or reference in an authority record, provide an option for the catalog user to "jump" to the appropriate place in an alphabetical display of headings that includes reference structures. Implicit in this recommendation is that a keyword search, while acknowledging the user's initial intention by searching for and returning a results list of bibliographic records, simultaneously searches authority records and provides the user with the option to alter his or her search strategy.

Reasons: Has the potential for improving both precision and recall through the use of controlled vocabulary without forcing the user to select a search that uses only controlled vocabulary.

Example: A keyword search of bibliographic records is performed using the term blimps.

Results: three bibliographic records are retrieved, two have the term in the title, one has the term in a note. However, the system also suggests another term (the preferred term) to search on, and a search on this term, Airships, will retrieve 63 records. The reference to the preferred term comes from an LCSH authority record. One option (of several) for displaying the results of the keyword search is given below.

$\begin{array}{llr}\text { Record \# } & \text { Full Title } & \text { Date } \\ 1 & \text { For additional information search for Airships } & 1992 \\ 2 & \text { Blimps \& U-boats : U.S. Navy airships in the battle of the Atlantic / J. Gordon Vaeth. } \\ 3 & \text { Blimps / Roxie Munroe } & 1989 \\ 4 & \text { Wings : the early years of aviation / Richard Rosenblum. } & 1980 \\ & {[\text { blimps appears in a note in the record for this title] }}\end{array}$

3. Provide a keyword-on-heading (a.k.a. keyword-in-heading, or keyword subject browse) search of subject headings from bibliographic and authority records that results in an initial display of headings (including reference structures) rather than of bibliographic records.

Reasons: Provides browsable access to reference structures for users who know that they want to consult a list of headings but may not have knowledge of initial words or word order in those headings, or who want to see all the headings that contain certain terms in order to make an informed selection among them.

Example:

Search term: tragicomedy

Results:

\section{Records Headings}

$0 \quad$ English drama (Tragicomedy)

Broader term $(\mathrm{s})$

2 English drama (Tragicomedy) - History and criticism

$55 \quad$ Tragicomedy

$\underline{\text { Broader term }(\mathrm{s})}$

Narrower term(s)

11 Tragicomedy-History and criticism.

1 Tragicomedy-History and criticism-Congresses.

1 Tragicomedy_-Study and teaching.

4. Provide a left-anchored (a.k.a. left-justified) search of subject headings and reference structures that results in a display of headings (including reference structures) rather than bibliographic records. [See also Recommendation 12 for display.]

Reasons: Provides browsable access to reference structures for users who know the beginning word or words of a heading.

Example: A browse search of the LC Subject Headings Index using the search string "Tumors" could produce the following results list (first page shown). 


\author{
Records Headings \\ 3 Tumor proteins. \\ Broader term $(s)$ : Proteins; Tumor markers \\ Narrower term $(s)$ : Alpha fetoproteins; [more] \\ 107 Tumors \\ Broader term $(s)$ : Pathology \\ Related term(s): Cysts (Pathology); Oncology \\ Narrower term $(s)$ : Adenoma; [more] \\ Also, subject headings beginning with the word Tumor; and subdivision Tumors under individual \\ organs and regions of the body, e.g. Foot-Tumors \\ 14 Tumors-Abstracts. \\ $1 \quad$ Tumors-Animal models. \\ 1 Tumors-Animal models-Atlases. \\ 4 Tumors-Atlases. \\ 1 Tumors-Blood-vessels.
}

5. In a display of a single bibliographic record, hyperlink subject headings to an alphabetical display of headings that includes reference structures.

Reasons: A hyperlink that retrieves only those bibliographic records that match a particular heading fails to show the searcher any variations of the heading (e.g., with different subdivisions) or any further references that may be useful. Both precision and recall are better served by hyperlinking to the alphabetical display of headings. It is more useful to take the user to the appropriate reference structure, where options can be explored, than to take the user directly to other bibliographic records.

6. Make it possible for users to limit searching to a particular subject heading system while still incorporating see references to guide the user to preferred terms, and incorporating or linking to the reference structures of that system to guide the user in broadening, narrowing, or changing the scope of a search.

Reasons: Conflicts exist among subject heading systems with different terms being selected for the same concept; limiting to a particular system increases precision in large databases by permitting the user to select the vocabulary most suited to his or her needs (e.g., MeSH for medical searchers, LCSH for more general searchers, LC Children's for younger users) without sacrificing access to reference structures.

7. Incorporate see-references from, and provide links to, reference structures from multiple subject heading systems in a single display of headings, making it possible for users to see an array of possibilities before making a selection. [See also Recommendation 13 concerning the labeling of headings from multiple systems.] (Note: As the number of subject heading systems included in a single display increases, the importance of having concise information in that display also increases.)

Reasons: The user may not have enough information to make an initial selection of subject heading system (e.g., MeSH or LCSH?), but may instead need to see the possibilities before determining which paths to follow.

Example: This example shows the application of Recommendations 7 and 13.

Search term: Arm

Results:

( $\mathrm{LC}=$ Library of Congress subject; $\mathrm{MeSH}=$ Medical subject $)$

\title{
Records Headings
}

16

12

1

1

1

1

2
Arm - (LC) [ Heading information]

Arm - (MeSH) [Heading information]

ARM - (MeSH)

See: $\underline{\text { Association of Radical Midwives (MeSH) [Heading Information] }}$

Arm—abnormalities - (MeSH] [Heading information]

Arm-Abnormalities. (LC)

Arm-Amputation - (LC) [ Heading information]

Arm-Amputation-Handbooks, manuals, etc. - (LC)

Arm—anatomy \& histology (MeSH] [ Heading information] 
$1 \quad$ Arm-congresses $(\mathrm{MeSH})$

8. Make it possible to incorporate and link to name (including personal, corporate, and geographic names) and title reference structures in subject indexes that include these entities. Reasons: These entities can serve as subjects, and access to them is improved by inclusion of reference structures. In the old dictionary catalogs this was not a problem; it became a problem as soon as the shift to divided catalogs occurred.

9. Make it possible to apply limits but still provide access to the appropriate reference structures; and for each heading displayed, indicate the number of bibliographic records that have that heading and that conform to the limits applied. Reasons: If the user can make use of and have access to either the reference structures, or the limiting features of a system, but not both simultaneously, it forces the user to make a difficult choice. Either option sacrifices the advantages of the other. Using reference structures without limiting functionality diminishes precision; using limiting without reference structures diminishes recall.

\section{Part II: Recommendations for Display of Headings and Reference Structures}

10. Because the display of headings is a kind of reference structure, preserve punctuation and capitalization in the display of headings (i.e., do not normalize the display).

Reasons: Punctuation and capitalization clarify meaning in headings and their reference structures.

11. Use the punctuation and subfielding present in controlled vocabularies to create meaningful arrays of headings.

Reasons: The browsable display of subject headings, arranged not just alphabetically but also following the syntactic structure of the terms, is itself a form of reference structure, as it brings similar terms together more effectively than do normalized alphabetical displays. As with the display of broader, narrower, and related terms, it makes both the clarification and the redirection of a subject quest easier. Example: This shows the application of recommendations 10 and 11. Note the retention of punctuation and capitalization; and the use of punctuation and subfielding to create a meaningful display
Children
Children-Age determination
Children-Crimes against
Children-Diseases
Children-Research
Children-Africa, Southern
Children-Italy
Children-Tennessee
Children, Adopted
See Adopted Children
Children, Blind
Children, Prehistoric
Children (Christian theology)
Children (International law)
Children (Roman law)
Children as consumers
Children in motion pictures
Children of artists

12. In a search resulting in a left-anchored list of headings, display at least one term immediately preceding the term that most closely matches the search. [See also recommendations 4 and 22]. Reasons: Providing a display of close matches is a form of reference structure. Many closely related headings share the same opening wording and are thus alphabetically adjacent. It makes it obvious to the user that there are preceding headings; in other words, it makes it clear that they are indeed in an index; and in the correct place in that index. Example: This shows the application of Recommendations 12 and 22. Recommended display resulting from a browse 
search on power semiconductors:

Power semiconductor industry

\section{Power semiconductors}

Power series

Power series rings

Power shovels

Power shovels_Electric driving

Power spectra

Power steering

13. When see references from different vocabulary sources (e.g., MeSH and LCSH) or having different functions (e.g., topical subject and form/genre) are displayed together, identify the source or function. [See also Recommendation 7] Reasons: It is confusing to have almost identical or conflicting references displayed without any qualification that explains their presence.

Example: See the example for Recommendation 7.

14. Display number of postings associated with a heading.

Reasons: Displaying the number of postings enables the user to see whether broadening or narrowing the search through the use of the subject reference structures is desirable.

15. Display broader, narrower, and related terms; group broader terms together, related terms together, and narrower terms together. Display the groups in the following order: broader, related, narrower.

Reasons: Users may wish to broaden, change, or narrow the scope of their queries. Displaying just one or two categories of related terms restricts the freedom of the user to take advantage of these different methods of altering the scope of a query.

16. Identify broader, related, and narrower terms as broader, related, and narrower.

Reasons: Displaying related terms is more useful if the nature of the relationship is indicated explicitly.

Example: This shows the application of Recommendations 15 and 16.

$\begin{array}{ll}\begin{array}{c}\text { Mycology } \\ \text { Broader term }(s):\end{array} & \text { Botany } \\ \begin{array}{l}\text { Related term }(s): \\ \text { Narrower term }(s):\end{array} & \begin{array}{l}\text { Microbiology } \\ \text { Fichenology } \\ \text { Medical mycology }\end{array} \\ \text { Mycologists }\end{array}$

17. Make it possible for an institution to choose to display complex see and see also references "up front" - specifically the 260 and 360 fields. Also, as an option, make it possible to display general notes (e.g., 667, 680).

Reasons: These complex references are useful and give necessary explanations to users of the catalog

Examples:

Ecology

See also subdivision Environmental aspects under subjects, e.g. Agricultural chemicals_Environmental aspects;

Nuclear power plants_Environmental aspects; and headings beginning with the word Ecological Zaire

Subject Usage: This heading is not valid for use as a subject. Works about this place are entered under Congo (Democratic Republic)

18. Systems should offer institutions an array of options for the placement of references (BT, RT, NT, Complex see references, 7XX references) relative to headings.

Reasons: The decision to select a particular option will depend on the size and complexity of the catalog and the perceived needs of the users of that catalog. 
19. Make it possible to display reference structures with 0 postings if a heading exists in the database in subdivided form only (i.e., make suppression of reference structures with 0 postings optional and/or dependent on the existence of a given heading whether subdivided or alone)

Reasons: If a main heading exists only in subdivided form, the references to that main heading are still useful to users of the catalog.

Example:

\section{Records Headings}

$0 \quad$ Luxemburg (City)

See: Luxembourg (Luxembourg)

The "see" reference takes the user to:

\section{Records Headings}

$0 \quad$ Luxembourg (Luxembourg)

$1 \quad$ Luxembourg (Luxembourg)—Buildings, etc.

3 Luxembourg (Luxembourg)—History

Note that the see reference would be appropriate, since the heading has associate records in its subdivided form.

20. Missing links in multi-level links: make it possible to display 0-posting headings if any see-also references associated with the headings have postings.

Reason: Unless these 0-posting headings are displayed, a user of a particular catalog may be unable to navigate to broader or narrower headings that are of interest. Headings with 0-postings are sometimes needed in order to link two terms that do have postings, if one term is a broader term for the 0-postings heading and another term is a narrower term for that 0-postings heading.

Example: A library has some bibliographic records with the heading, Soil science; and some bibliographic records with the heading, Soil conservation; but no bibliographic records with the heading, Soil management. It would still be desirable to have a browse search on the term "Soil management" result in a display like the following:

\section{Records Headings \\ $0 \quad$ Soil management \\ Broader term (s): $\underline{\text { Soil science }}$ \\ Narrower term $(s)$ : $\underline{\text { Soil conservation }}$}

21. In the cases where there are non-unique see-references, display all the possibilities.

Reasons: See references are not necessarily unique, and the user should be given all the possible choices in order to make an informed selection.

Example:

Labor and laboring classes: see Working class

$\underline{\text { Labor movement }}$

Labor

\section{Part III: Recommendations for Providing Navigation within and among Reference Structures}

22. Make it possible for the user to browse the entire vocabulary, not just the elements of the vocabulary that are an exact match to the user's search [See also recommendation 12].

Reasons: Adjacency is a form of reference structure; often, adjacent words or terms are similar in meaning. Example: see the example for Recommendation 12.

23. Provide hyperlinks from displayed references; these hyperlinks should take the user to the appropriate place in a headings display (i.e., a display that includes the reference structure).

Reasons: A hyperlink that goes directly to bibliographic records fails to show the searcher any subdivided instances of the hyperlinked heading, or any further references to narrower, broader, or related terms. 
24. Make use of references between and among subject heading systems (e.g., LCSH and MeSH; Canadian Subject Headings and Répertoire de vedettes-matière; etc.). These references are found in the 7XX fields in subject authority records.

Reasons: Users searching in online catalogs with multiple subject heading systems should be directed to equivalent terms in all systems.

Examples:

Asian Canadians (CSH)

Related terms: $\quad$ Chinese Canadians (CSH)

Japanese Canadians (CSH)

South Asian Canadians (CSH)

Aviation $(\mathrm{MeSH})$

Equivalent terms: $\quad$ Canadiens d'origine asiatique (RVM)

Broader terms: $\quad$ Transportation $(\mathrm{MeSH})$

Narrower terms: $\quad$ Aircraft $(\mathrm{MeSH})$

Space Flight $(\mathrm{MeSH})$

Equivalent terms:

Aeronautics (LCSH)

Part IV: Concerns for the Future: Recommendations for Librarians for Modifications of Existing Library Practices in the Creation of Subject Reference Structures

25. Encourage the use of $7 \mathrm{XX}$ fields in subject authority records when a library employs more than one subject heading system.

Reasons: This will enable systems to use these fields for the generation of references. [See also recommendation 24].

26. Address the problem of reference structures for geographic names that are no longer valid for use as subjects by [i] creating separate subject authority records for geographic names that can be used as both subjects and corporate names; or [ii] by implementing the coding already present in the MARC 21 authority format that indicates whether a reference is valid for subjects and/or names

Reasons: The current practice makes it extremely difficult for systems to provide the appropriate reference structure for both subject and descriptive usage of geographic names. 